\title{
Correction to: Trunk Reaction Time and Kinematic Changes Following Slip Perturbations in Subjects with Recurrent Low Back Pain
}

\author{
Paul S. Sung (i) and Pamela Danial \\ Doctoral Program in Physical Therapy/Motion Analysis Center, Herbert H. and Grace A. Dow College of Health Professions, \\ Central Michigan University, Health Professions Building 1220, Mt. Pleasant, MI 48859, USA
}

(Published online 27 October 2020)

\section{Correction to:}

Annals of Biomedical Engineering, Vol. 46, No. 3, pp. 488-497

https://doi.org/10.1007/s10439-017-1972-8

This erratum is to correct the results section on page 490.

There was an average age difference between groups $(25.03 \pm 2.79$ years in the control group vs. $30.21 \pm$ 13.76 years in the LBP group; $t=-2.32, p=0.02$ ). The body mass index (BMI) was compared between groups, and there was no statistical difference (23.79 \pm
4.98 in the control group vs. $24.93 \pm 5.27$ in the LBP group; $t=-0.91, p=0.36)$. In the LBP group, the level of pain based on the visual analog scale (VAS) was $16.90 \pm 6.66 \mathrm{~mm}$; and their level of disability based on the Oswestry Disability Index (ODI) was $13.69 \pm 10.76 \%$, which indicated a minimal disability level.

Publisher's Note Springer Nature remains neutral with regard to jurisdictional claims in published maps and institutional affiliations.

Address correspondence to Paul S. Sung, Doctoral Program in Physical Therapy/Motion Analysis Center, Herbert H. and Grace A. Dow College of Health Professions, Central Michigan University, Health Professions Building 1220, Mt. Pleasant, MI 48859, USA. Electronic mail: drpsung@gmail.com

The original article can be found online at https://doi.org/10. 1007/s10439-017-1972-8. 